\title{
Caruaru Arretado: Utilização de Problem-Based Learning (PBL) em um Curso de Desenvolvimento de Jogos para Alunos do Ensino Médio
}

\author{
Marília Lima $^{1}$,Elisson Rocha ${ }^{1}$, Wylliams Santos $^{12}$, Elyda Xavier $^{12}$, \\ Mirele Moutinho ${ }^{1}$,Jorge Fonseca $^{12}$ \\ ${ }^{1}$ Instituto de Informática - Universidade de Pernambuco (UPE) \\ Caruaru - PE - Brasil \\ ${ }^{2}$ Centro de Informática - Universidade Federal de Pernambuco (UFPE) \\ Recife - PE - Brasil \\ \{marilianayara, elissonrochaa, elydalaisasx, mirelemoutinho\}egmail.com, \\ wbs@upe.br, jcbf@cin.ufpe.br
}

\begin{abstract}
Show clearly the PBL methodology and its application in a game development course for high school students; it is a study based on action research method, using data collection descriptive method; it was observed that the withdrawal of the students was more than $50 \%$, but the students had the opportunity to build games from the theme Smart Cities, and develop their knowledge actively.
\end{abstract}

Resumo. Mostrar de forma clara a metodologia PBL e sua aplicação em um curso de desenvolvimento de jogos para alunos do Ensino Médio; trata-se de um estudo baseado no método de pesquisa-ação, utilizando para coleta de dados o método descritivo; foi observado que a desistência dos alunos foi superior a $50 \%$, mas os alunos tiveram a oportunidade de construir jogos, a partir do tema Cidades Inteligentes, e desenvolver seu conhecimento de forma ativa.

\section{Introdução}

O PBL (Problem-Based Learing) é uma metodologia de ensino e aprendizado que trata o aluno como sujeito ativo, visto que este vai em busca de seu próprio conhecimento, tendo uma relação com o professor para sanar suas dúvidas [Rocha and Santos 2016].

A aplicação da metodologia PBL é um processo culturalmente desafiador, uma vez que a sociedade está, no âmbito educacional, acostumada a se comportar de maneira passiva [Oliveira et al. 2012]. Essa passividade é empregada em todos os níveis da educação brasileira, incluindo o Ensino Médio. Na grande maioria das instituições, as aulas são ministradas de forma que o professor é tido como elemento central, enquanto os alunos recebem o conhecimento teórico, e pouco o aplicam na prática, não adquirindo assim a vivência ideal na construção do aprendizado.

Seguindo esse pressuposto, o presente artigo tem o intuito de propor um modelo pedagógico para suporte à utilização da metodologia PBL em um curso de desenvolvimento de jogos com foco em Cidades Inteligentes. Este modelo foi aplicado em uma escola pública da cidade de Caruaru, PE. 
V Congresso Brasileiro de Informática na Educação (CBIE 2016)

Anais dos Workshops do V Congresso Brasileiro de Informática na Educação (CBIE 2016)

\section{Referencial Teórico}

O PBL é um modelo de ensino bastante inovador e teve suas primeiras práticas na área médica. A Universidade de McMaster (Canadá) e de Maastricht (Holanda) foram as primeiras a adotar este modelo, seguida de outras instituições, como Harvard [Pires et al. 2010].

A base deste modelo educacional é o problema estruturado pelo professor, e de acordo com [Pires et al. 2010] "os problemas são apresentados para motivar o aprendizado de conceitos, permitindo que os alunos realizem uma simulação prática do que terão que fazer fora do ambiente acadêmico, propondo, planejando e executando soluções".

Dentro da metodologia do PBL, além do professor, existem os papéis do tutor e do aluno; os tutores representam um papel de instrutor ativo para introduzir o aluno no cenário proposto para a resolução de problemas, cabendo a este o papel de colaborador em seu processo de aprendizagem [Santos et al. 2011].

\section{Metodologia}

Para aplicar a metodologia PBL e verificar seus pontos positivos e negativos, o estudo foi baseado no método de pesquisa-ação, uma vez que neste método os pesquisadores estão presentes na realização da pesquisa, interferindo de forma ativa. Por essa razão, também foi realizada inicialmente a coleta de dados através do método descritivo, utilizando a observação para coletar os dados na medida em que a pesquisa foi sendo desenvolvida.

\section{Modelo Proposto}

Tendo como base as características apresentadas e com o intuito de melhorar a qualidade do aprendizado no ensino médio, foi proposto um modelo metodológico, conforme ilustrado na Figura 1. O modelo busca uma adaptação do método atual de ensino do curso de desenvolvimento de jogos, através da aplicação da metodologia PBL.

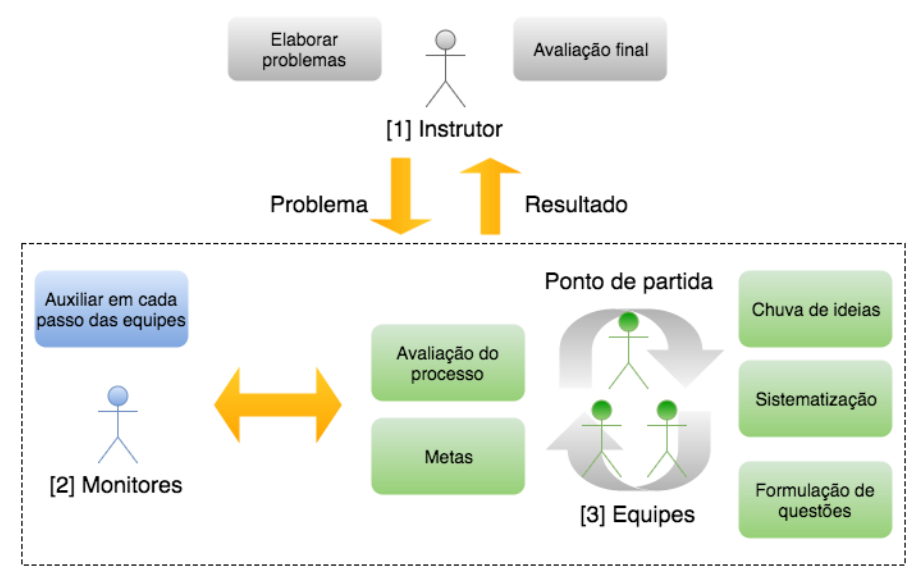

Figura 1. Modelo PBL aplicado no curso de desenvolvimento de jogos (Adaptado de [Rocha and Santos 2016])

Neste modelo, o instrutor apresenta as características do professor na metodologia PBL, e é através dele que os alunos receberão o embasamento teórico, como também é o mesmo que irá elaborar os exercícios para os alunos, e realizar a avaliação do projeto final. 
Os monitores representam a equipe tutorial no PBL, a qual tem a finalidade de auxiliar os alunos, apresentar as ideias para resolução do problema (chuva de ideias), organizando-as e verificando o que é essencial (sistematização), além de formular as questões e metas a partir dessa verificação, para que se consiga resolver o exercício proposto.

No momento em que o conteúdo é ministrado, não é recomendado que o instrutor explique todo o conceito que será estudado para a construção de cada etapa do jogo. Assim, os alunos devem ir em busca dos conhecimentos necessários à resolução dos problemas, resolvendo também situações que podem surgir no decorrer do mesmo.

É importante que tanto o instrutor como os monitores, no momento de esclarecer dúvidas, escolham a cada semana um aluno de cada equipe para falar das contribuições e possíveis problemas que tiveram até aquela monitoria (Sessão Tutorial). A partir das características apresentadas anteriormente, por existir poucos monitores, o professor também poderá atuar como tal para suprir as possíveis necessidades que os alunos venham a ter.

O esquema metodológico desse modelo está dividido em 4 partes. A primeira parte consiste na explanação teórica necessária, seguida da segunda parte, que é um tutorial do jogo modelo. Na terceira parte, foram indicados problemas para que as equipes desenvolvessem suas respectivas soluções e, finalmente, chegando na quarta parte, que é o desenvolvimento do jogo. Visto que o PBL é uma metodologia que busca sempre a resolução de problemas vinculados à realidade, foi proposto às turmas que toda a temática da resolução dos exercícios e execução do projeto estivesse associada ao tema de Cidades Inteligentes.

O projeto é parte integrante do programa de extensão da Universidade de Pernambuco, campus Caruaru, denominado Caruaru Arretado, por isso a escolha desse tema. O programa tem o propósito de estimular na cidade de Caruaru a temática de Cidades Inteligentes, sendo a universidade proponente e executora de soluções que transformem a cidade.

\section{Resultados e Discussão}

Inscreveram-se para participar do curso de desenvolvimento de jogos um total de 44 alunos de ensino médio que estudam em uma escola pública do município de Caruaru. Entretanto, apenas um pequeno percentual compareceu às aulas. Os alunos foram divididos em duas turmas, com dois instrutores, em dias diferentes.

No início do curso, as turmas eram compostas por 11 alunos cada (50\% dos matriculados), no final a quantidade de alunos foi 7 numa turma, e na outra apenas 1 aluno comparecia às aulas $(18,18 \%)$.

A metodologia do PBL, da forma que foi empregada no curso de desenvolvimento de jogos não apresentou resultados satisfatórios, já que o percentual de desistência dos alunos foi muito grande. Por isso, busca-se analisar quais fatores foram fundamentais para a evasão e propor uma nova elaboração das problemáticas que serão vivenciadas em sala de aula.

Diante de uma análise no cenário atual, foi visto que um possível problema pode estar no esquema metodológico do curso, onde o mesmo trabalha com exemplos, para 
V Congresso Brasileiro de Informática na Educação (CBIE 2016)

Anais dos Workshops do V Congresso Brasileiro de Informática na Educação (CBIE 2016)

depois trabalhar com os problemas reais (criação do jogo). Esse pode ser um fator forte para o grande número de desistências, já que o PBL apresenta uma abordagem com foco em uma problemática de forma continuada.

Para [Zaqueu and Netto. 2013] é importante que o professor seja um sujeito passivo no processo de ensino e apresendizagem dos estudantes, mas proporcione um ambiente estimulante e motivador, mediante questionamentos a respeito do tema estudado,sendo essa caracteristica proveniente da metodologia do construtivismo, que em alguns aspectos é semelhante a metodologia do PBL.

\section{Considerações Finais e Trabalhos Futuros}

$\mathrm{O}$ artigo apresentado descreveu a aplicabilidade da metodologia PBL em um curso de programação de jogos para alunos do ensino médio. Entretanto, os resultados obtidos não foram satisfatórios, visto que houve um índice grande de desistências por parte dos alunos.

Como trabalho futuro, pretende-se aprimorar o modelo proposto, com o objetivo de minimizar a evasão dos alunos que estiveram no curso de desenvolvimento de jogos, a fim de que se possa vivenciar os benefícios que o PBL pode proporcionar, que incluem a melhoria do espírito de liderança e comunicação.

Podemos citar como sugestões de melhorias imediatas: a) criar uma única turma, ofertando apenas um horário para o curso, concentrando assim os interessados e evitando a dispersão;b) melhorar a divulgação sobre os benefícios adquiridos ao participar do curso, como a realização de premiação, a entrega de certificados, participação em eventos da Universidade de Pernambuco e, finalmente, o início da construção de seu futuro profissional; e c) garantir a ligação de fato do curso com disciplinas do currículo dos alunos do ensino médio, como matemática, física e inglês, fortalecendo a importância dessa carga complementar, com a abordagem diferenciada do conteúdo.

\section{Referências}

Oliveira, E. A., Tedesco, P., and Chiu, T. P. T. (2012). Creating personalized and distributed virtual learning spaces through the use of i-collaboration 3.0. In Intelligent Virtual Agents, pages 477-479. Springer.

Pires, M. G., Bertoni, F. C., and Angelo, M. F. (2010). Aprendizagem Baseada em Problemas Aplicada ao Ensino de Compiladores em Engenharia de Computação. In $P B L$ 2010 Congresso Internacional, pages 8-12, São Paulo, Brazil.

Rocha, Elisson, L. N. and Santos, W. (2016). Problem based learning in the project management classroom. In 13th CONTECSI International Conference on Information Systems and Technology Management, pages 2740 - 2741, São Paulo, Brazil. TECSI.

Santos, S., Campos, F., Pinto, A., Chagas, U., and Lizárraga, M. (2011). Aplicando a Estratégia de Avaliação Autêntica em uma Residência de Software Baseada em PBL. In VII Conferência Internacional de Educação em Engenharia e Computação, pages $1-1$.

Zaqueu, Ana Cláudia Molina, D. C. R. and Netto., A. V. (2013). Curumim: A Robótica Educacional como Proposta Metodológica para o Ensino. Anais dos Workshops do Congresso Brasileiro de Informática na Educação. Vol. 2. No. 1. 2013. 